\title{
Research on interaction and communication in English teaching
}

\author{
Jing Li \\ Department of Foreign Languages, Qinhuangdao Institute of Technology, Qinhuangdao, Hebei, China
}

\begin{abstract}
In recent years, with the continuous improvement of English teaching way, the interaction and communication way in English teaching has become an important means to improve English teaching. This paper illustrates the benefits of interaction and communication in English teaching, and introduces three interaction and communication ways in English teaching - unilateral communication between teachers and students, multi-directional communication between teachers and students, and multi-level communication between teachers and students, and carries out experimental teaching based on these three ways. This paper uses the factor analysis to analyze the student performance in listening, speaking, reading and writing, and determines the proportion of performance in these four aspects according to the analysis results. This paper evaluates the effect of role of three interaction and communication ways in English teaching according to the fuzzy comprehensive evaluation. The results show that the unilateral communication between teachers and students is slightly superior.
\end{abstract}

Keywords: English teaching; interaction and communication; factor analysis; fuzzy comprehensive evaluation

\section{INTRODUCTION}

English is an official international language. English teaching is the most important thing in China's education. Over the years, the traditional English teaching way occupies the dominant position, and the purpose for the students is examination, and the students could not listen, speak read and write. The original English education makes the language teaching theory and linguistics as the sole theoretical source. Internationally, the language teaching is not limited to linguistics, which is the intersection of multiple disciplines, thus constructing a new teaching model $[1,2]$. The teaching interaction is an important communication way of information, idea and emotion. The verbal communication and non-verbal communication can be as an interactive mode [3]. In 2012, the scholar, He Jing stressed that the interaction between teachers and students in language teaching seriously affects the students' learning effect, which is a part of the hidden curriculum. A good teacher-student relationship is helpful to smooth implementation of teaching. The author discusses the interaction between teachers and students and the relationship between English learning effect of middle school students by the use of the quantitative research and qualitative research, and investigates the factors that affect the interaction be- tween teachers and students in English teaching in secondary school. The result shows that most of the current English teachers pay attention to the perspective of classroom teaching, but ignore the communication with students after class; just pay attention to explanation of English subject knowledge, but ignore spiritual communication with the students. The author points out that, the students' perception on English teachers has a great relevance with their likeability of English and the performance in English class. A good teacher-student interaction is helpful to improve the students' attitudes of learning knowledge from the teachers. Meanwhile, the author discusses the important measures to establish a good teacher-student interaction in the perspective of English teachers [4]. In 2014, the scholar, Zhang Yingying pointed out that, in the current English teaching classroom, lack of interaction is an important reason to influence the student performance. The author carries out the comparative analysis of the interactive teaching way and non-interactive teaching way by taking the students of U-CAN Secondary School of New Oriental as the analysis object, which is mainly based on the following four aspects: the learning attitude, reading attitude, mastery degree and communicative competence. The results show that the interactive teaching way can not only improve the students' ability to master 
knowledge, but also help them to improve the language skills. Take the interaction and communication way in English teaching as research object, this paper focuses on the improvement of English teaching method to enhance the English teaching level [5].

\section{INTERACTION AND COMMUNICATION OF ENGLISH TEACHING}

In English classroom teaching, the role of interaction and communication between teachers and students, and between teachers and researchers is more important, as shown in Figure 1.

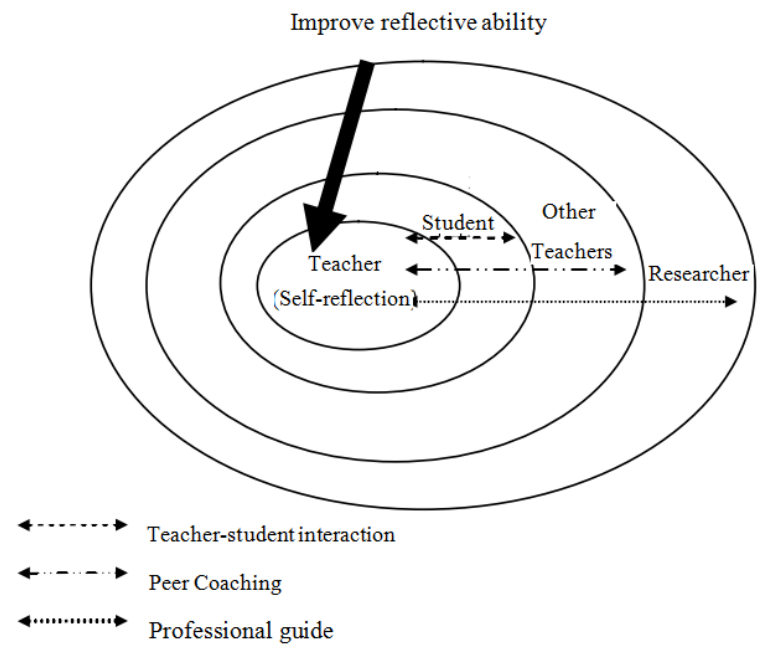

Figure 1. Communication between teachers and relevant personnel

The teachers need to organize classroom, and guide the students to do independent learning, inspire the students' self-learning, answer the students' doubts, completely extract the relevant information of network, and expand the students' knowledge scope. The interaction and communication in English teaching has the following benefits [6].

(1) Organize classroom

English teachers often view the lecture content, syllabus and teaching objective as the teaching basis. The interaction and communication between teachers and students is helpful for the teachers to understand Basic English level of the students and student learning ability, thus designing reasonable classroom ways, so that all students are able to be integrated into the classroom teaching.

(2) Inspire students learning

In the actual teaching process, many teachers find that many students do not know how to learn. For example, the students dare not to speak, and do not have perseverance in English learning. In this case, the interaction and communication between teachers and students is helpful to guide the students' independent learning, in order to avoid the consequences of students' blind learning. The teachers can encourage the students to develop their own learning goals and learning programs, and also to speak in language learning. The teachers can also set up discussion groups among students, and let them do mutual learning guidance, in order to inspire the students.

(3) Answerer of doubts

"The teacher, preaches, instructs and dispels doubt." Answering the students' doubts is the essence of teaching. The teacher should not only solve the students' puzzles related to the basic knowledge, but also solve the difficulties of students in the learning methods. Therefore, the teachers need to communicate with students after class, but also provide online answers for the students by the use of the e-mail, microblog, WeChat and other network platforms.

\section{EVALUATION OF ROLE OF INTERACTION AND COMMUNICATION WAY}

In modern English teaching classroom, the interaction and communication way includes the bilateral communication, multi-directional communication, and multi-level communication between teachers and students. The bilateral communication between teachers and students refers to the communication between each student and teacher, as shown in Figure 2. The multi-directional communication refers to a certain communication between students in addition to the communication between each student and teacher, as shown in Figure 3. The multi-level communication between teachers and students refers to a certain grading between students, and feedback of all problems to the teachers, as shown in Figure 4.

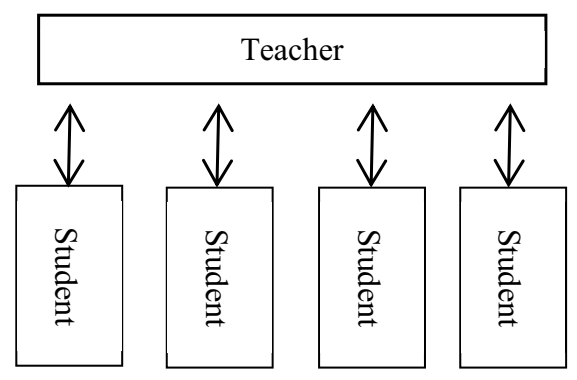

Figure 2. Bilateral communication between teachers and students

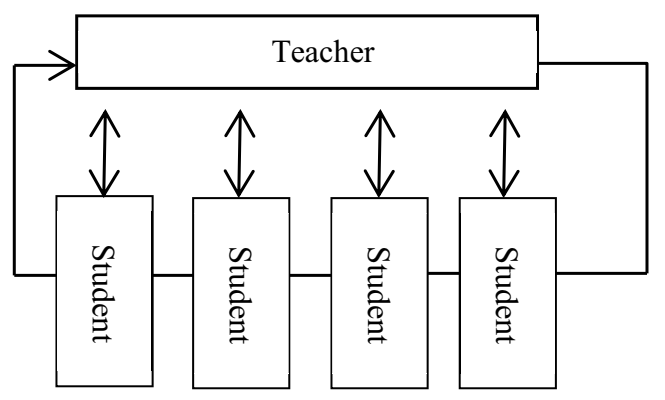

Figure 3. Multi-directional communication between teachers and students 


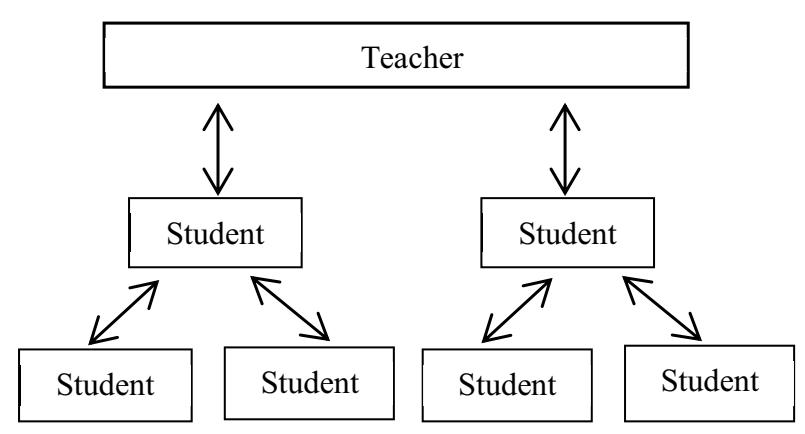

Figure 4. Multi-level communication between teachers and students

\subsection{Data statistics}

In English classroom, whether the interaction and communication between teachers and students is valid mainly relies on the student performance in English listening, speaking, reading and writing. Based on three different interaction and communication ways the bilateral communication, multi-directional communication, and multi-level communication between teachers and students, this paper sets up three experimental classes, with 30 students per class, and makes statistics of the performance of three experimental classes in listening, speaking, reading and writing [7]. The results are shown in Table 1.

Table 1. Statistical results of performance in listening, speaking, reading and writing

\begin{tabular}{lllll}
\hline No. & Listening & Speaking & Readier & Writing \\
\hline 1 & 61 & 55 & 72 & 38 \\
$\ldots$ & $\ldots$ & $\ldots$ & $\ldots$ & $\ldots$ \\
30 & 56 & 42 & 55 & 47 \\
31 & 62 & 83 & 75 & 72 \\
$\ldots$ & $\ldots$ & $\ldots$ & $\ldots$ & $\ldots$ \\
60 & 66 & 76 & 82 & 79 \\
61 & 81 & 39 & 75 & 52 \\
$\ldots$ & $\ldots$ & $\ldots$ & $\ldots$ & $\ldots$ \\
90 & 54 & 72 & 82 & 45 \\
\hline
\end{tabular}

In Table 1, "1-30" represents the performance of experimental class in bilateral communication between teachers and students; "31-60" represents the performance of experimental class in the multi-directional communication between teachers and students; "61-90" represents the performance of experimental class in multi-level communication between teachers and students. Therefore, this paper carries out the factor analysis to obtain the proportion of each performance.

\subsection{Factor analysis}

Factor analysis is to integrate the variables with a complex relationship into few factors. In multivariate analysis, it is also a statistical method of dimensional- ity reduction process [8]. The factor analysis is carried out based on the statistical results of the performance in listening, speaking, reading and writing. The gravel diagram is shown in Figure 5.

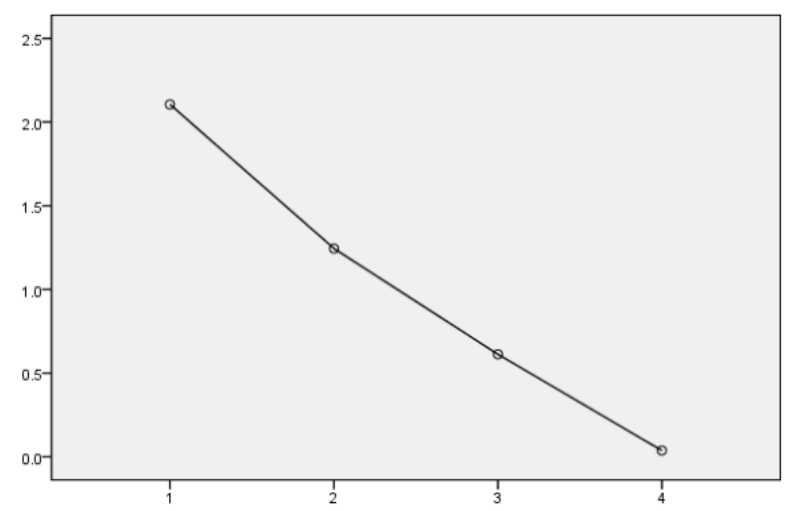

Figure 5. Gravel diagram

Figure 5 indicates the relative importance of listening, speaking, reading and writing, thus determining the proportion of each factor on this basis, and evaluating the effectiveness of three interaction and communication ways by the use of the fuzzy comprehensive evaluation.

\subsection{Fuzzy comprehensive evaluation}

Under normal circumstance, the fuzzy comprehensive evaluation involves in three amounts $[9,10]$. Assuming that there are $n$ factors related to the evaluated object, recording as $U=\left\{u_{1}, u_{2}, \ldots, u_{n}\right\}$, it is called as the factor set. Assuming that there are $m$ comments, recording as $V=\left\{v_{1}, v_{2}, \ldots, v_{n}\right\}$, it is called as the judgment set. The position of each factor is different, its role is also different, so there is a measurement standard, namely, weight, recording as $A=\left\{a_{1}, a_{2}, \ldots, a_{n}\right\}$.

\subsubsection{Comprehensive evaluation steps}

The fuzzy comprehensive evaluation steps are as follows:

(1) To set the factor set $U=\left\{u_{1}, u_{2}, \ldots, u_{n}\right\}$.

(2) To set the judgment set $V=\left\{v_{1}, v_{2}, \ldots, v_{n}\right\}$.

(3) To judge a single factor and obtain.

$$
r_{i}=\left\{v_{i 1}, v_{i 2}, \ldots, v_{i n}\right\}
$$

(4) To construct the comprehensive evaluation matrix:

$R=\left[\begin{array}{cccc}r_{11} & r_{12} & \cdots & r_{1 m} \\ r_{21} & r_{22} & \cdots & r_{2 m} \\ \vdots & \vdots & & \vdots \\ r_{n 1} & r_{n 2} & \cdots & r_{n m}\end{array}\right]$

(5) Comprehensive evaluation: For weight $A=\left\{a_{1}\right.$, $\left.a_{2}, \ldots, a_{n}\right\}$, to calculate $B=A \circ R$, and make evaluation according to the maximum membership principle. 


\subsubsection{Definition of operator $\circ$}

In the comprehensive evaluation, according to different definitions of the operator $\circ$, there are different models.

(1) Model I : $M(\wedge, \vee)$ - determination type of principal factor

Calculation method

$b_{j}=\max \left\{\left(a_{i} \wedge r_{i j}\right), i=1,2, \cdots, n\right\}(j=1,2, \cdots, m)$

The model evaluation results are determined by the factors playing a major role in the overall evaluation, which are suitable for the case of viewing the optimal individual judgment as the optimal comprehensive evaluation.

(2) Model II : $M(\bullet, \vee)$ - prominent type of principal factor

Calculation method

$b_{j}=\max \left\{\left(a_{i} \bullet r_{i j}\right), i=1,2, \cdots, n\right\}(j=1,2, \cdots, m)$

The model is somewhat similar to model I , but it is more refined than model I . It not only highlights the main factors, but also takes into account other factors. This model is applicable to the range that is not applicable to the model I. That is, a variety of factors could not be distinguished, but require refining.

(3) Model IV: $M(\wedge, \oplus)$ - type of taking a small upper bound

Calculation method

$b_{j}=\min \left\{\left(1, \sum_{i=1}^{n}\left(a_{i} \wedge r_{i j}\right)\right)\right\}(j=1,2, \cdots, m)$

In the use of the model, there is a need to pay special attention: Each $a_{\mathrm{i}}$ could not be too large, otherwise $b_{j}$ may be 1 ; each $a_{\mathrm{i}}$ could not be too small, otherwise $b_{j}$ is equal to the sum of each $a_{\mathrm{i}}$, thus leading to the loss of relevant evaluation information of a single factor.

(4) Model V: $M(\wedge,+)$ - Balanced average type Calculation method

$b_{j}=\sum_{i=1}^{n}\left(a_{i} \wedge \frac{r_{i j}}{r_{0}}\right)(j=1,2, \cdots, m)$

Where, $r_{0}=\sum_{k=1}^{n} r_{k j}$. The model is suitable for the case of too large or too small element in the comprehensive evaluation matrix $R$.

The model established in this paper uses the operator with the determination type of principal factor.

\subsubsection{Evaluation results}

According to the results of the factor analysis, the proportion $A$ of listening, speaking, reading and writ- ing can be determined.

$A=(0.5,0.3,0.15,0.05)$

The data in Table 1 are classified according to the types of the experimental class, thus solving the average performance of each experimental class, and establishing the comprehensive evaluation matrix $R$ on this basis:

$R=\left[\begin{array}{lll}0.28 & 0.21 & 0.27 \\ 0.23 & 0.27 & 0.22 \\ 0.30 & 0.26 & 0.31 \\ 0.19 & 0.25 & 0.19\end{array}\right]$

Based on the model I - $M(\wedge, \vee)$, to calculate two weights [11]

$B=A \circ R=(0.28,0.27,0.27)$

As can be seen from the evaluation results, the impact of three interaction and communication ways on the students' English learning is basically the same, and the unilateral communication between teachers and students is slightly superior.

\section{CONCLUSION}

This paper evaluates the impact of different types of interaction and communication ways in English teaching on the students' English learning through the principal component analysis and fuzzy comprehensive evaluation. The calculation results show that the unilateral communication between teachers and students is slightly superior, because the communication between students is likely to affect their perception in English teaching. When these suggestions are comprehensively reflected to the teachers, it is likely to mislead the teachers' teaching ideas. Therefore, combined with the actual situation, the model established in this paper can accurately evaluate the interaction and communication ways in English teaching. In addition, the model can also be applied to the research of the interaction and communication ways in teaching other disciplines. Of course, in different evaluation systems, the proportion of a variety of factors is different. Therefore, there is a need to re-set the proportion.

\section{REFERENCES}

[1] Richards, J.C. \& Ho. B. 2001. Reflective Thinking through Journal Writing [A]. Richards beyond Training [C]. Cambridge: CUP, pp.153-171 J.C.

[2] Kumaravadivelu, B. 2012. Language Teacher Education for a Global Society. London: Routledge.

[3] Liu Yao, Dai Haiyan. 2010. Research review of teacher-student interaction in classroom. Educational Science Research, (6): 66-69. 
[4] He Jing. 2012. Impact of Teacher-student Relationship on English Learning of Middle School Students from the Perspective of Recessive Subject. Master's Thesis of Xi'an International Studies University.

[5] Zhang Yingying. 2014. Applied research of interactive teaching in senior English reading teaching -- A case study of U CAN Secondary School of Beijing New Oriental. Master's Thesis of Ningxia University.

[6] Wu Lirong, Gao Suxia, Dong Guoying, et al. 2011. Self-learning: An effective practice of professional development of teachers. Journal of Hebei Normal University (Educational Science Edition), (12): 52-55.
[7] Sheng Shengke. 2010. SPSS Statistical Analysis from Introduction to Proficiency. Beijing: Tsinghua University Press,

[8] Zhou Yongzheng, et al. 2010. Mathematical Modeling. Shanghai: Tongji University Press.

[9] Wan Xinghuo. 2007. Probability Theory and Mathematical Statistics. Beijing: Science Press.

[10] Wang Xiaoyin, et al. 2010. Mathematical Modeling and Mathematical Experiments. Beijing: Science Press.

[11] Zhuo Jinwu, et al. 2010. Application of Matlabin Mathematical Modeling. Beijing: Beijing University of Aeronautics and Astronautics Press. 